\title{
0935 SMARTRISK'S THEORY OF CHANGE FOR PREVENTION OF INJURY AMONG CANADIAN YOUTH
}

P R Groff*, S Marshall, B Baker Correspondence: SMARTRISK, 36 Eglinton Avenue West, Suite 704 Toronto, Ontario M4R 1A1, Canada

10.1136/ip.2010.029215.935

The model employed by SMARTRISK to develop the Theory of Change for Youth was adapted from one proposed by the Aspen Institute Roundtable on Social Change. It is recognised as a best practice in the art of theory construction. The process begins with identifying the end goal an organisation wishes to achieve, the ultimate intended outcome(s) of any strategies. Next, a process of backwards mapping is undertaken whereby any preconditions (intermediate and shorter term outcomes) to arrive at the final goal are noted. Throughout this process, each outcome is assessed to determine whether it will necessarily lead to the next outcome in the model, or whether a planned intervention by the organisation is necessary. In addition, any underlying assumptions about objectives or the links between them are made explicit. The authors will be presenting the Theory of Change for Prevention of Injury among Canadian Youth, and illustrating specific application of the Theory of Change with evaluated examples of SMARTRISK's injury prevention programming for youth. 